\title{
Technological Procedure for Recycling of PET Waste for Sustainable Environment Concept Achievement
}

\author{
Ali I. Al-Mosawi, Shaymaa Abbas Abdulsada \\ Faculty of Materials Science and Engineering, University of Miskolc, Miskolc, Hungary \\ Email: qkoali76@uni-miskolc.hu, qksha86@uni-miskolc.hu
}

How to cite this paper: Al-Mosawi, A.I. and Abdulsada, S.A. (2018) Technological Procedure for Recycling of PET Waste for Sustainable Environment Concept Achievement. Open Access Library Journal, 5: e4327. https://doi.org/10.4236/oalib.1104327

Received: January 12, 2018

Accepted: January 28, 2018

Published: January 31, 2018

Copyright $\odot 2018$ by authors and Open Access Library Inc.

This work is licensed under the Creative Commons Attribution International License (CC BY 4.0).

http://creativecommons.org/licenses/by/4.0/

\section{(c) (i) Open Access}

\begin{abstract}
In this research, polyethylene terephthalate bottles (PET) waste was added to styrene-butadiene rubber (SBR) to manufacture road bumps, as a technological procedure for recycling this PET waste, in order to maintain a clean and sustainable environment. Polyethylene terephthalate bottles were cut as grooved strips and added to bump SBR batch with various percentages (0 $100 \mathrm{pphr}$ ). Mechanical tests were performed before and after the addition of PET waste including tensile strength, hardness, and resilience. Nanoparticles of carbon black, zinc oxide and sulfur were used, and compare the results with samples with micro particles additions. The result shows that the developed and manufactured bump SBR in this research conforms to the mechanical characteristics of the original bump model especially with nanoparticles additives, and the best results obtained with the nanoparticles additions.
\end{abstract}

\section{Subject Areas}

Material Experiment

\section{Keywords}

PET Waste, Road Bumps, SBR, Sustainable Environment

\section{Introduction}

A real revolution in the manufacturing of new compounds and materials occurs in the mid of the $20^{\text {th }}$ century, and the most important of all these materials was the production of plastic, which was used in all aspects of practical life due to its many advantages, including the ease of its formation and manufacturing. The global production of this important material has increased widely, which led re- 
searchers to call the last half of $20^{\text {th }}$ century as "plastic age". However, although there are benefits of plastic, it was accompanied by many negative results, including the accumulation of millions of tons of waste of this material, which has a very long decay and it has devastating effects on the human health and all elements of the environment [1] [2] [3] [4] [5].

Studies have shown that plastic wastes have a degradation life such as polyethylene, polyvinyl chloride, and many others can't be treated like any other industrial waste, where they produce the most dangerous toxins and harmful gases when burned like dioxins and heavy metals which cause air, water, and soil pollution. Scientific research has shown that plastic materials cause a large number of health problems because they are basic components and additives during manufacturing and formation. One of the compounds involved in the manufacturing of plastic bottles is polyethylene terephthalate (PET), as well as Diethylhydroxylamine (DEHA), which both toxic compounds cause cancer if taken directly [6] [7] [8] [9]. In the case of exposure to these bottles to heat or washing and repeated use, the chemical granules, which are located in the walls of these bottles, will decompose and dissolve from the inner walls of the bottle and then be mixed with the foods. Therefore, these wastes must be recycled so as to ensure the safety of the environment and have economic feasibility [10] [11] [12] [13] [14].

\section{Materials and Methods}

Materials: Styrene butadiene rubber (SBR); PET waste as grooved strips with $100 \mathrm{~mm}$ length and $2 \mathrm{~mm}$ width; carbon black as a nanoparticles (14 nm); Zinc oxide with $(50 \mathrm{~nm})$ nanoscale particles; Stearic acid 800, Dioctyl phthalate plasticizer (DOP); Antioxidant; Sulfur as a nanoparticles (55 nm); Wax-E as Lubricant; and Tetramethyl thiuram disulfide (TMTD) as accelerator. The percentage of materials is shown in Table 1. Two roll mills Comerio Ercole Busto Avsizo machine was used to for mixing materials and manufacturing of batch.

Table 1. Contents of Rubber Batch for Speed Bump.

\begin{tabular}{ccc}
\hline Supplier & pphr & Compounding Ingredients \\
\hline IndiaMART InterMESH Ltd & 100 & SBR \\
Reinste Nano Ventures Pvt. Ltd. & $0-40$ & Carbon black (13 nm) \\
EPRUI Nanoparticles \& Microspheres Co. Ltd & 3 & Zinc oxide (50 nm) \\
Liuyang Sanji Chemical Trade Co., Ltd. & 1 & Stearic acid 800 \\
ChemCeed LLC & 1 & DOP \\
Henan GP Chemicals Co. Ltd. & 1.5 & TMTD \\
Nanjing Union Rubber Chemicals Co. Ltd. & 1.5 & Antioxidant \\
Sky Spring Nanomaterials, Inc. & 1.5 & Sulfur (55nm) \\
Faith Industries PVT. Ltd. & 0.3 & Wax-E \\
Waste & $0-100$ & PET waste
\end{tabular}




\section{Testes and Samples Standards}

1) Tensile Test: Tensometer T10 device was used to carry out tensile test according to the ASTM D412 standard by. The samples of this test have a circular cross-section with $6 \mathrm{~mm}$ diameter and $115 \mathrm{~mm}$ length.

2) Hardness Test: Wallace bead load hardness instrument was used to accomplish this test. This test was done according to the ASTM D2240 standard. Hardness samples dimensions are $40 \mathrm{~mm}$ diameter and $4 \mathrm{~mm}$ thickness.

3) Resilience test: this test was done according to ASTM D1054 standard with the resilience tester. Samples are placed in the furnace for 30 minutes at $50^{\circ} \mathrm{C}$ and then the test is performed.

4) Energy-dispersive X-ray spectroscopic micro-analyser (EDS): for PET has been done by Carl Zeiss EVO MA10 SEM, as shown in Figure 1.

\section{Results and Discussion}

One of the most important characteristics of rubber is that it can add $120 \%$ fillers due to its high elasticity. Figure 2 represents the hardness of road bumps as a function of PET waste content with nanoparticles and microparticles of $\mathrm{C}$, $\mathrm{ZnO}$ and $\mathrm{S}$ additives. The hardness of rubber bump will increase after adding PET strips because these strips will act as a reinforcing material for rubber which will raise the value of its hardness. The hardness increases with the increase in the PET additions. When comparing the results obtained from the nanoparticles of $\mathrm{C}, \mathrm{ZnO}$ and $\mathrm{S}$ additives and the results obtained with microparticles of $\mathrm{C}$, $\mathrm{ZnO}$, and $\mathrm{S}$ additives, we will see that the results obtained with nanoparticles are the best.

Figure 3 represents the tensile strength of road bumps as a function of PET waste content with nanoparticles and microparticles of $\mathrm{C}, \mathrm{ZnO}$ and $\mathrm{S}$ additives. The tensile strength of rubber will decrease when the PET waste is added and this decrease continues with the increase in the PET content. This is due to the fact that the PET will be a weakness points in the structure of the rubber, which

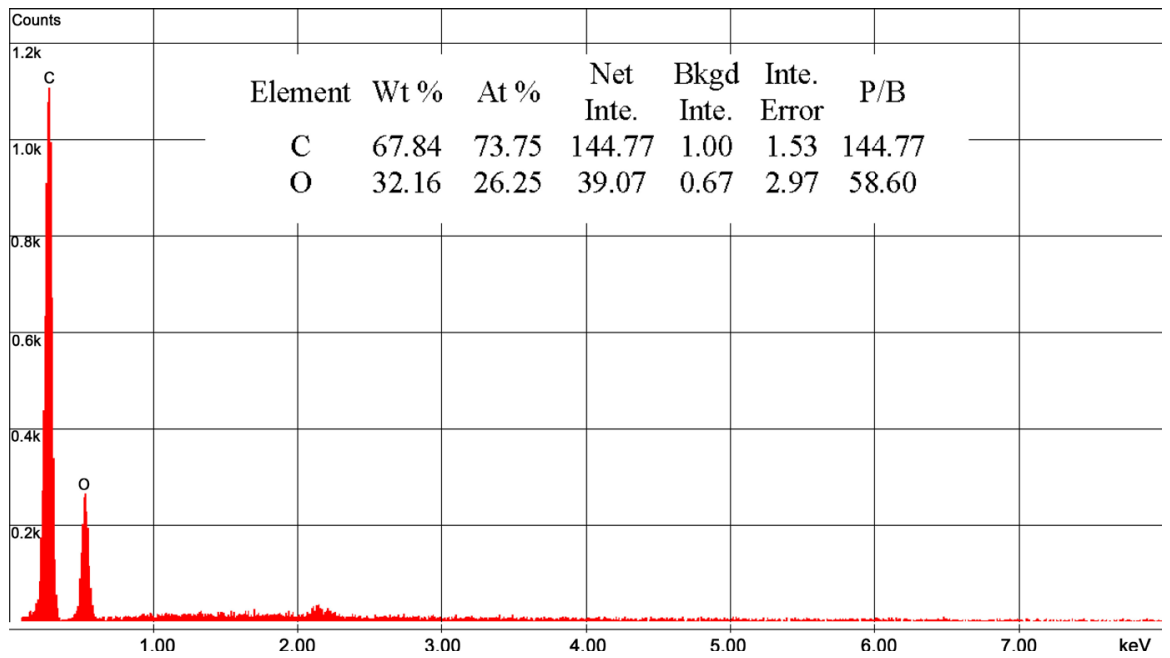

Figure 1. Energy-dispersive X-ray spectroscopic micro-analyser (EDS) for PET. 


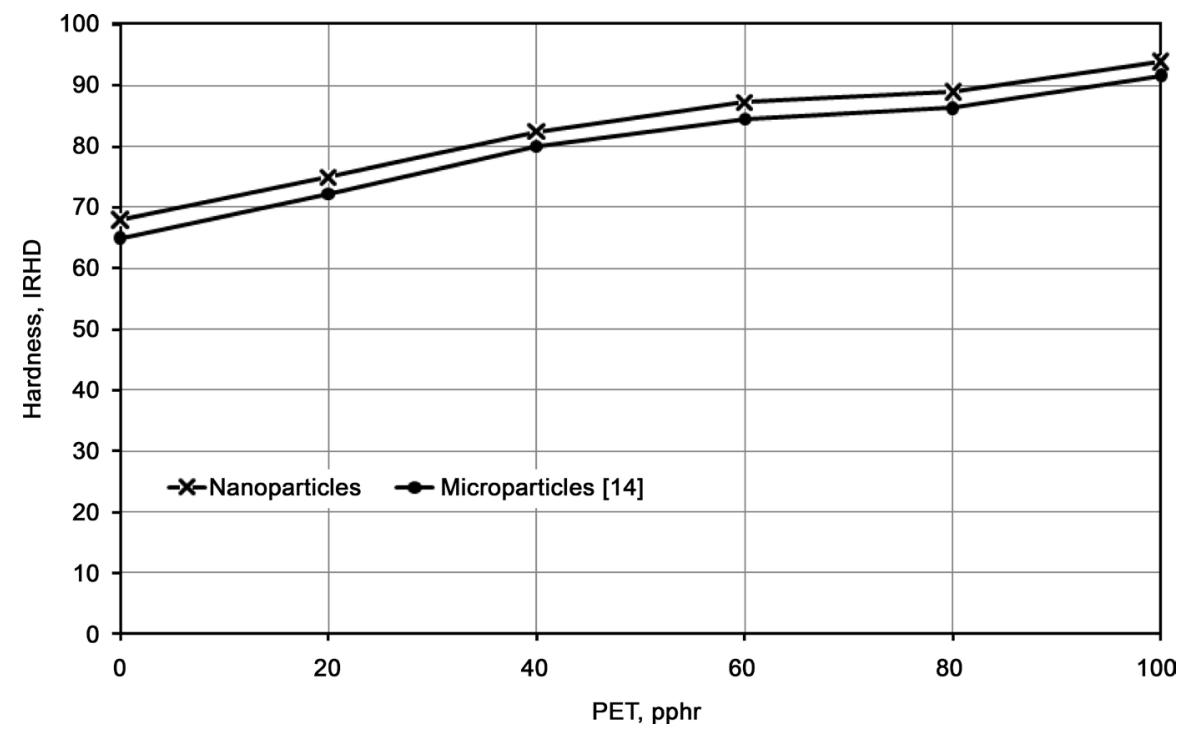

Figure 2. Hardness of Road Bump vs. PET Waste Content and Nanoparticles; Microparticles Additives.

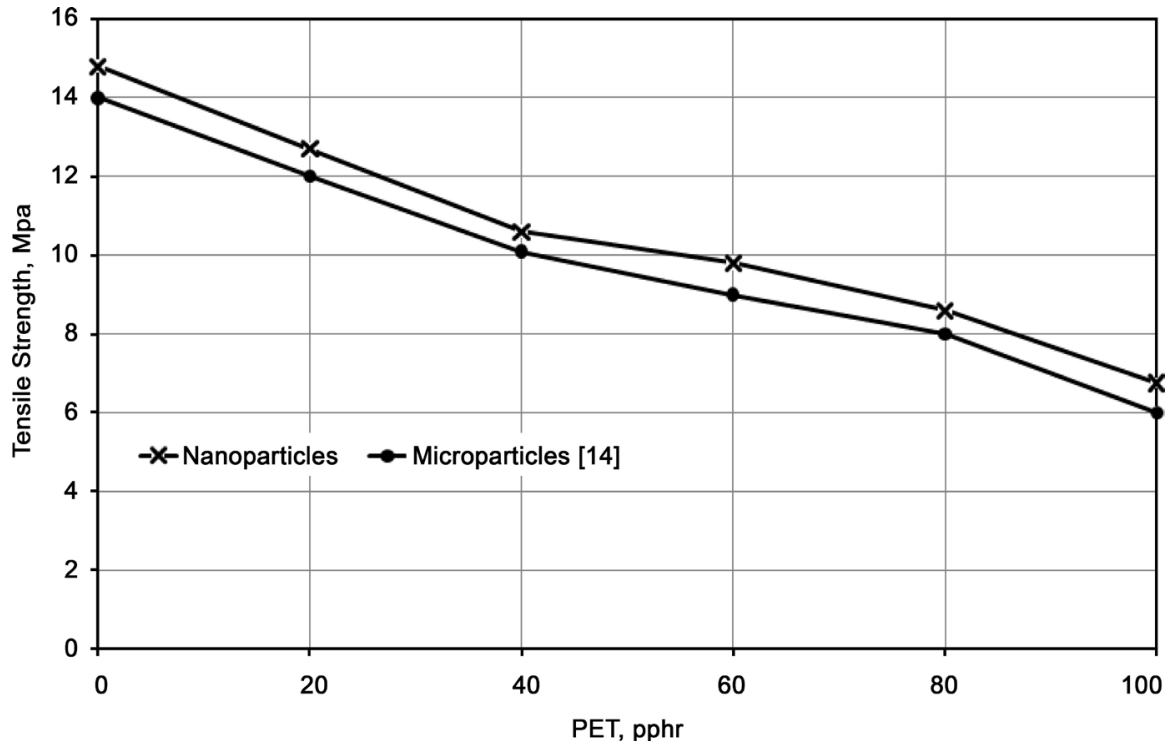

Figure 3. Tensile Strength of Road Bump vs. PET Waste Content and Nanoparticles; Microparticles Additives.

is reflected on the tensile strength and causes weakening, and this state is normal for the solid additives. Also, we can observe that the results obtained with nanoparticles are better than microparticles results.

Figure 4 represents the resilience of road bumps as a function of PET waste content with nanoparticles and microparticles of $\mathrm{C}, \mathrm{ZnO}$ and $\mathrm{S}$ additives. We can observe that the resilience value will decrease when adding PET waste and this decrease will be non-linear. Because these additions of the oxide lead to the formation of defects and gaps in the rubber structure and thus lead to a decline in resilience value. Also, the results obtained with nanoparticles are better than microparticles results. 


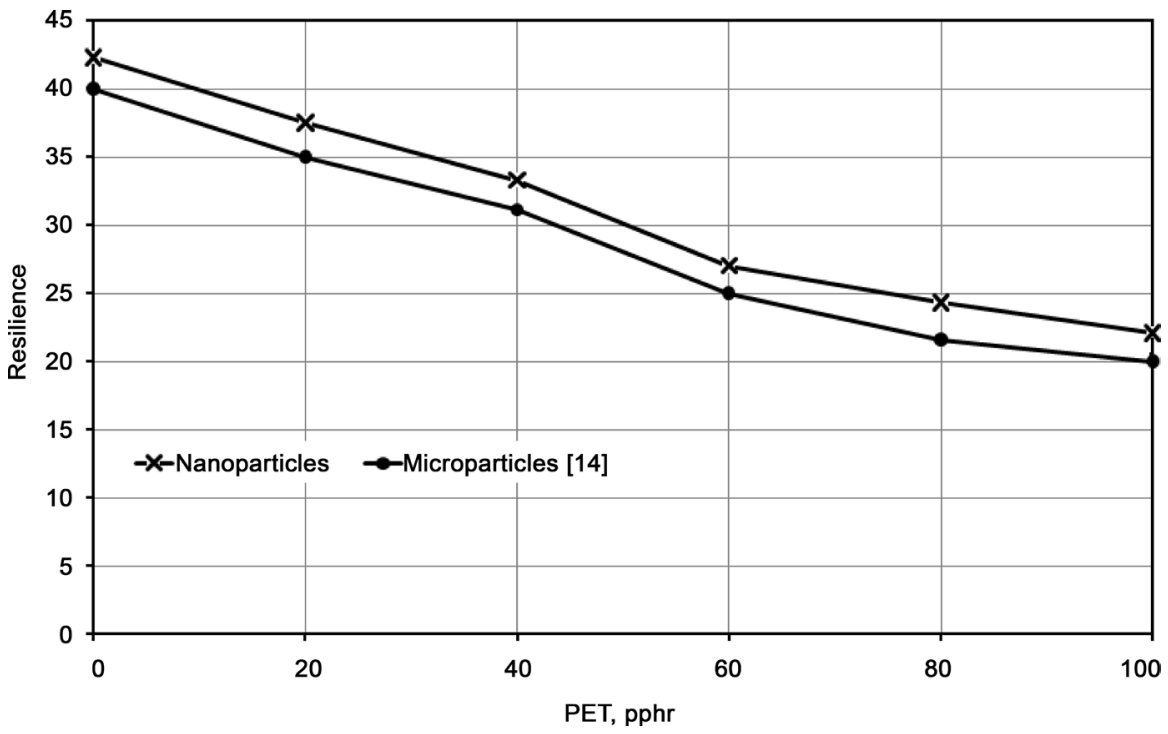

Figure 4. Resilience of Road Bump vs. PET Waste Content and Nanoparticles; Microparticles Additives.

\section{Conclusions}

Using of PET improves the hardness of SBR, but at the same time, the tensile strength and resilience have decreased at specific rates of PET addition. This change in properties was within the limits of international standards. As a result of the use of PET waste, the cost of manufacturing bumps has decreased significantly. Since the bumps manufactured in this research are a rubber material, it will have a longer operating life than the imported ones, which are manufactured from plastic instead of rubber. In addition, the environmental and health effects of PET waste can be eliminated because the rubber prevents PET from decomposing and it completely surrounds completely by rubber. The best results were obtained when adding nanoparticles of carbon black, zinc oxide and sulfur.

\section{References}

[1] Malik, A. and Grohmann, E. (2012) Environmental Protection Strategies for Sustainable Development. Springer, Netherlands. https://doi.org/10.1007/978-94-007-1591-2

[2] Khan, I. and Gundaliya, P.J. (2012) Utilization of Waste Polyethylene Materials in Bituminous Concrete Mix for Improved Performance of Flexible Pavements. International Journal of Scientific Research, 1, 57-58. https://doi.org/10.15373/22778179/SEP2012/21

[3] Central Pollution Control Board. (2003) A Support Manual for Municipal Solid Wastes, (Management and Handling) Rules. Vol. 2, CPCB, Delhi.

[4] Al-Mosawi, A.I., Abdulsada, S.A. and Rijab, M.A. (2017) Recycling Procedure of Plant Waste for Manufacturing Green Composite Material. Journal of Catalyst and Catalysis, 5, 211-214.

[5] Al-Mosawi, A.I. and Abdulsada, S.A. (2015) Recycling of Waste Materials. LAP Lambert Academic Publishing, Germany.

[6] Bach, C., Dauchy, X., Chagnon, M.-C. and Etienne, S. (2012) Chemical Migration in 
Drinking Water Stored in Polyethylene Terephthalate (PET) Bottles: A Source of Controversy. Water Research, 46, 571-583.

https://doi.org/10.1016/j.watres.2011.11.062

[7] Sax, L. (2010) Polyethylene Terephthalate May Yield Endocrine Disruptors. Environmental Health Perspectives, 118, 445-448. https://doi.org/10.1289/ehp.0901253

[8] Wanielista, M., Baldassari, T., Ryan, P., Rivera, B., Shah, T. and Stuart, E. (2008) Feasibility Study of Waste Tire Use in Pollution Control for Stormwater Management, Drainfields and Water Conservation in Florida. Final Report, Stormwater Management Academy, University of Central Florida.

[9] (2011) European Commission, Plastic Waste: Ecological and Human Health Impacts, Science for Environment Policy, In-Depth Reports.

[10] Al-Mosawi, A.I., Abdulsada, S.A. and Rijab, M.A. (2016) The Optimum Use of the Sunflower Husks Waste for Manufacturing of Environmentally Friendly Composite Material Contributes to the Sustainability of Natural Resources. Organization for Standardization and Quality Control (COSQC), No.4742, International Classification (Y02P60/148), Iraqi Classification 3.

[11] Szasz, A. (2009) Shopping Our Way to Safety: How We Changed from Protecting the Environment to Protecting Ourselves. University of Minnesota Press, Minnesota.

[12] Al-Mosawi, A.I., Abdulsada, S.A. and Al-Maamori, M.H. (2017) Mechanical Properties of Tri Sustainable NBR/Cement Waste/Rice Husks Silica Blend. Journal of Polymer \& Composites, 5, 29-31.

[13] Vasudevan, R. (2006) Utilization of Waste Plastics for Flexible Pavement. Vol. 34, Indian Highways, Indian Roads Congress, New Delhi, 105-111.

[14] Al-Maamori, M.H., Al-Mosawi, A.I. and Abed, M.A. (2015) Design and Manufacture of Road Bumps Using Waste of Polyethylene Terephthalate Bottles (PET). Central Organization for Standardization and Quality Control (COSQC), No.4244, International Classification (C01B31/08), Iraqi Classification 34. 